\title{
LOS ACTOS PÚBLICOS DEL CONTADOR Y LA ÉTICA, UN PROBLEMA EN ENRON CORP
}

\author{
Mg. Elsa Esther Choy Zevallos*
}

\begin{abstract}
RESUMEN
Contador Público, dos palabras que expresan la función del profesional contable. El carácter público, ubica su actuación como "visto y sabido por todos" y su deber es decir la verdad, opinar con absoluta independencia y transparencia, para evitar situaciones como el problema Enron Corp. y sus Auditores.
\end{abstract}

\section{INTRODUCCIÓN}

En el Perú, uno de los aspectos más sensibles que enfrenta la sociedad es el problema de valores éticos. En la medida que los ciudadanos quiebren o alteren las reglas de vida y los principios morales que orientan la conducta correcta del individuo en sociedad, aumentará la desconfianza y falta de credibilidad.

En las universidades del país la carrera profesional del contador público, recibe una formación ética e inducida de manera natural a la justicia. Su técnica, cuyas raíces se hallan en la partida doble, lo obliga a moverse en la lógica de dar a cada cual lo que le corresponde. Tal herencia cultural del contador público impone que actúe con sentido de un equilibrio siempre presente, muy necesario para esta labor.

La actuación del contador público, cuyo rol está basado en temas relacionados con los negocios, las finanzas y administración, necesita criterios de probidad pública para obrar con rectitud en esta función que de carácter privado se convierte en público cuando sale al servicio de organizaciones "visto o sabido por todos".

Cabe anotar que recientemente fue publicado en un diario de mayor circulación un artículo sobre la quiebra de una de las más grandes empresas de Estados Unidos: Enron Corp., cuando se hizo público que sus estados financieros no expresaban la verdad; había forzado una situación financiera de sobreapalancamiento, los efectos económicos y sociales fueron inmediatos: caída de acciones, desempleo, desconfianza $y$ falta de credibilidad entre sus clientes.

El efecto también alcanzó a los Auditores que participaron en la elaboración de esta información financiera, una firma tan importante como es Arthur Andersen, que trastocó la ética profesional al prestar sus servicios profesionales a Enron Corp. tanto en contabilidad como en auditoría, y no informar adecuadamente.

Lamentablemente, tal como lo señala el artículo, "el tema ocupa titulares de The Wall Steet Journal, la edición de febrero 2002, The Economist muestra en su portada a un grupo de hombres vestidos con terno encerrados dentro de una jaula la cual exhíbe un cartel que dice "Don't feed the accountants"; en español "No alimente a los contadores". De esta forma se presenta a estos profesionales como una especie peligrosa y temible de la que habría que cuidarse".

En este contexto se cuestiona la participación de los auditores financieros en la

* Doctoranda UPG 
caída de Enron Corp., una firma tan importante a nivel mundial, conformada por auditores de reconocida trayectoria, respetada en todos los países; pero que frente a lo sucedido, puede desaparecer por no informar con transparencia y porque su independencia profesional se pone en duda.

Frente a los graves hechos ocurridos, motiva tratar el tema sobre la actuación del contador público y su cuestionamiento a la pérdida de independencia, sobre todo cuando se actúa como auditor y se aceptan altos cargos en organizaciones empresariales, que le da una inmoral ventaja, que le permite obtener datos estrictamente confidenciales y comparar estrategias, resultados, con empresas similares.

El tema ha desarrollado conceptos sobre el contador público, diversas formas de actuación profesional, preparación académica y delimitación del campo de actuación con el fin de que no deteriore su imagen, todo lo contrario, sirva de instrumento académico para enriquecer los conocimientos de estudiantes universitarios y profesionales.

\section{ANTECEDENTES DE LA PROFESIÓN CONTABLE}

La profesión del Contador Público surgió como una necesidad imperiosamente reclamada por la industria y el comercio por su gran desarrollo a través de la historia económica del mundo.

En el siglo XIX intervinieron los peritos tenedores de libros, cuya misión principal era descubrir las transacciones fraudulentas y localizar los errores. Al término de este siglo, y principios del siglo $\mathrm{XX}$, comenzaron a circular los tratados $y$ textos de contabilidad cuya introducción en el pensamientos de los estudiantes de la época alcanzó una gran influencia ya que muchos de los textos fueron adoptados en los planes de estudios. Los estudios académicos mediante sistemas y métodos eminentemente pedagógicos han formado promociones de contadores públicos con una preparación sólida tanto en economía política, finanzas, derecho y la contabilidad misma, actuando como auditores, consultores, asesores financieros y contables.

En cuanto a la legislación profesional en el Perú, así como en otros países donde existe la profesión contable, ha venido estructurándose a tono con el tiempo y las circunstancias propias de cada país, teniendo en cuenta los servicios y la responsabilidad de esta especialidad.

En el Perú el Contador Público todavía no ha alcanzado una legislación que verdaderamente le favorezca como a toda profesión liberal. En este sentido la Ley 13253 considera como profesionales a los contadores públicos, mercantiles y prácticos.

\section{DESARROLLO CONCEPTUAL DE CONTADOR PÚBLICO}

Con la finalidad de presentar el concepto de la palabra compuesta contador público, tanto etimológico como doctrinario, se ha revisado diversas obras y los autores tienen diferentes criterios, tal es así que uno de ellos señala que Contador es: "El que cuenta. El que tiene por empleo, oficio o profesión llevar cuenta y razón la entrada y salida de caudales, haciendo el cargo a las personas que los perciben y recibiéndolas en data lo que pagan, con los recados de justificación correspondiente. Persona nombrada por el Juez competente o por las mismas partes, para liquidar alguna cuenta"'. 
Al referirse sobre Público, el mismo autor dice: "Notorio, patente manifiesto, visto o sabido por todos. Dícese de la potestad o autoridad para hacer una cosa, como contrapuesta o privado"2.

Al no existir la etimología de la palabra Contador Público se ha conceptuado en forma aislada conforme las transcripciones que se acaba de hacer, se trata de la unión convencional de dos palabras, con la finalidad de expresar la función profesional en el campo de la contabilidad donde se determina la especialidad, ocupación y su preparación académica universitaria.

Su valor etimológico del vocablo CONTADOR, procede del latín "computador", significa el que tiene por empleo, oficio o profesión de llevar cuenta y razón de la entrada y salida de los bienes y valores, es decir, se refiere a la actividad inherente a la persona, designando la función de contar en têrminos de números traducidos en cuentas y partidas propias de una contabilidad.

Cuando esta función de carácter privado sale al campo de los negocios y el servicio del contador se diversifica, necesita que esta potestad y autoridad se patente, visto o sabido por todos, de allí el vocablo público. Por consiguiente la palabra compuesta Contador Público nace de la yuxtaposición de estos vocablos cuyo significado origina la identificación del profesional contable.

En cuanto a la definición doctrinaria, está circunscrita en las normas y principios universales de contabilidad. Eric KOLER, define a la Contaduría Pública como: -Profesión del contador público; específicamente, el ofrecimiento al público de las habilidades contables profesionales independientes, consistentes de modo principal en: Planeamiento e instalación de sistemas de contabilidad financiera y de costos. auditorías; investigaciones; informes 10 dictámenes) basados en las auditorías practicadas; asesoramiento sobre la estructura administrativa y políticas financieras, así como los servicios relacionados con impuestos, principalmente impuesto sobre la renta. Los servicios del contador público se ofrecen al público en general, en contraste con el empleo de un contador privado, sobre una base de tiempo completo que sirve a una sola empresa comercial. Los servicios ofrecidos podrán ser generales, o bien, restringidos a un tipo particular de servicio contable. El contador público no tiene obligación de prestar servicios a todos los que se lo soliciten" ${ }^{3}$.

El Contador Público es quien ejerce la práctica de la Contabilidad Pública y en conexión con esa práctica ofrece sus servicios retribuidos al público.

\section{SITUACIÓN ANALÍTICA DEL CON- TADOR PÚBLICO}

La Ley de Profesionalización 13253, en su artículo cuarto, señala que corresponde a los Contadores Públicos autorizar toda clase de balances, peritajes y tasaciones de su especialidad. Operaciones de auditoría $y$ estudios contables con fines judiciales $y$ administrativos

El ejercicio contable exige al profesional no sólo capacidad en el desempeño de sus funciones, sino también la responsabilidad moral constituye uno de los pilares de la formación profesional; esto se encuentra establecido en el Código de ética profesional de los contadores públicos. El Código de ética profesional establece las responsabilidades y conocimientos técnicos culturales, morales y socioeconómicos,

= Ibid, p. 2010. 
estableciendo las condiciones de imparcialidad en relación de sus actuaciones profesionales ante el Estado, frente al servicio de la tributación y en general los actos inherentes a la categoría profesional.

El análisis de Eduardo Cárdenas Saldarriaga, en el diario El Peruano de la sección Economía 18-9-00, dice: "ninguna profesión se encuentra más ligada a la información que la contabilidad, sobre todo en el entorno de las organizaciones, cualquiera que fuere su tipo o dimensión. De allí que la demanda de la información debe pasar; quiérase o no, por el tamis contable, más aún si ha de incidir en las decisiones, que todos esperan sean siempre acertadas y oportunas"4.

En otro párrafo añade: "Es obvio que nos referimos a quienes son responsables del registro de los datos concernientes a hechos económicos o transacciones que por diversos conceptos efectúan las organizaciones: los contadores públicos" 5 .

El mismo autor dice: "El contador público, eje central de la organización, debe ser el artífice que interprete y solucione los requerimientos de los usuarios; que dicte las pautas y organice la información, interactuando con las otras áreas y con los profesionales y ejecutivos de la empresa, de manera tal que la información solicitada por ellos conlleve el valor agregado de ser útil para la toma de decisiones apropiadas y oportunas"6.

El autor en su análisis refiere que siendo el Contador Público centro del manejo de información de cada organización, es el que puede estar ubicado en todos los niveles de las organizaciones como gestor de conocimiento, denominación que se le atribuye a Peter Druker. El contador público conoce la realidad empresarial y los problemas que presenta la gestión financiera; está capacitado como auditor, analista financier : buen comunicador y facilitador de con flictos. Todo un reto para la profesión quier deberá canalizar sus conocimientos habilidades y valores profesionales con criterios de excelencia y oportunidad.

En cuanto a la actuación profesiona. del Contador Público, si los autores consideran que la Contabilidad es la piedra angular de la dirección de negocios o como e. articulador supremo y coordinador de las actividades mercantiles, es lógico pensar que al frente de esta labor debe estar un profesional imbuido de todo conocimiento $e$ idoneidad para afrontar conflictos relacionados con esta actividad.

Los directivos y funcionarios responsables de la marcha administrativa de una empresa necesitan de información contable que les ayude a realizar inteligentemente su trabajo y cuando desean utilizar estas informaciones con visión al futuro deben entender el probable significado de una cifra o tendencia, sus limitaciones y bajo qué circunstancias puede tener un significado diferente del que aparentemente proporciona. Los directivos y funcionarios para tomar sus decisiones no requieren saber cómo proyectar, instalar y verificar la exactitud de un sistema de contabilidad, puesto que estas importantes funciones las confían a los contadores públicos, quienes se convierten en artífices de la estructuración contable de una empresa como elemento fundamental para la buena administración y ejecución de programas.

Los servicios del profesional contable conllevan una importante responsabilidad, pues generalmente se les contrata para resolver problemas financieros y legales complicados de cuya relación depende que los 
clientes puedan cumplir mejor sus compromisos contraídos.

La responsabilidad del Contador respecto al mundo exterior descansa no sobre un contrato, sino en el principio de los agravios que cause. La responsabilidad es un concepto que tiene una relación directa con la moral y ética del individuo que orienta su propia conciencia y se expresa en las creencias y compromisos sociales, culturales, religiosos, fraternales, cívicos $e$ ideológicos, adquiridos en su relación con la sociedad.

\section{CONCLUSIONES}

1. La responsabilidad del Contador Público respecto al mundo exterior no sólo se encuentra encuadrado en normas técnicas sino también en normas éticas.

2. Dentro del extenso campo de actuación del Contador Público, que abarca diversas disciplinas y especialidades, se ubica la auditoría como una de las actividades más expuestas a ser cuestionadas por su independencia.

3. La formación del profesional contable debe contemplar conocimiento, habilidades y valores éticos y son requeridos de forma conjunta, para demostrar competencia en el manejo diario de su quehacer profesional.

\section{RECOMENDACIONES}

1. Para el Cuerpo Colegiado lo sucedido últimamente con la firma Auditores Arthur Andersen y su cliente Enron Corp. no debe ser motivo de desprestigio a la profesión, más bien deja lecciones para hacer cambios importantes en la actuación del profesional contable, como hacer una revisión de sus normas éticas y ajustarlas al mundo globalizado actual.

2. Es necesario ante esta problemática que atraviesa el país, de cambios profundos en materia económica y financiera y los conflictos que de ella se deriven, contemplar estudios de especialización en valores éticos, por este motivo, las Facultades Contables de las Universidades del país, así como las Escuelas de Posgrado, deberían incorporar en sus Planes de Estudios cursos sobre principios éticos y morales.

3. El Colegio de Contadores Públicos de Lima debe fomentar valores éticos a través de charlas, seminarios y conferencias; puesto que la actuación profesional del Contador Público no sólo se debe a la aplicación de los principios contables al preparar y presentar los estados financieros, sino su actuación como persona y profesional.

\section{BIBLIOGRAFÍA}

1. CARDENAS SALDARRIAGA, Eduardo. El Peruano, sección Economía, 18-9-00.

2. DRUCKER, Peter F. Gerencia para el futuro: El decenio de los 90 y más allá, Editorial Norma, 1996, Santafé de Bogotá-Colombia.

3. KOHLER L., Eric Diccionario para Contadores, Editorial UTEHA, 1ra edición, 1981, México D.F.

4. Luyo, Edwin. La ética de la profesión contable y las empresas. El Comercio, 27-06-02, p. B2. 